\title{
Stereochemically Constrained Linear Peptides. Conformations of Peptides Containing a-Aminoisobutyric Acid
}

\author{
R. Nagaraj, N. Shamala, and P. Balaram* \\ Contributionfrom the Molecular Biophysics Unit, Indian Institute of Science, \\ Bangalore 560012, India.
}

\begin{abstract}
H}$ NMR studies of the protected a-aminoisobutyric acid containing peptides Z-Aib-Pro-Aib-Ala-OMe and Z-AibPro-Aib-OMe suggest that these molecules adopt well-defined conformations in solution. Evidence for type III $\beta$-bend structures is presented and an incipient $3_{10}$ helical conformation is proposed for the tetrapeptide. The interpretation of the NMR data is further substantiated by the crystal structure of the tetrapeptide. which shows two consecutive type III $\beta$ bends in the solid state.
\end{abstract}

The determination of the conformation of peptides in solution has been the subject of considerable recent interest. ${ }^{I, 2}$ The application of NMR methods to the conformational analysis of small linear peptides has been restricted by the fact that these molecules have a large number of conformational states of similar energies available, resulting in a dynamic averaging of the NMR spectral parameters. Cyclic peptides have therefore proved popular systems for investfgation, not merely because of their biological relevance but also as a result of their comparatively restricted range of conformations, which renders them amenable to detailed analysis. ${ }^{3}$ Despite the difficulties associated with the study of flexible peptide systems, NMR studies of protected oligopeptides have been reported. ${ }^{4-8}$ Evidence for folded structures in linear peptides containing proline has been obtained by ${ }^{1} \mathrm{H}$ NMR ${ }^{9,10}$ In principle, stereochemical constraints may be introduced into linear peptide sequences by the use of conformationally restricted amino acid residues. The steric hindrance introduced by a-alkylation of $\alpha$-amino acids was first noted in synthetic investigations. ${ }^{11,12}$ Subsequent theoretical analysis showed that there is considerable restriction of conformational freedom in peptides derived from $\alpha, \alpha$-dialkylamino acids. ${ }^{13-15}$ The antibiotic alamethicin ${ }^{16,17}$ and related microbial peptides suzukacillin, ${ }^{18}$ emmerimicins, ${ }^{19}$ and antiamoebins ${ }^{20}$ contain a high proportion of a-aminoisobutyric acid. The amino acid sequences proposed for alamethicin on the basis of extensive ${ }^{1} \mathrm{H} \mathrm{NMR}^{16}$ and mass spectrometric $^{\mathrm{i} 7}$ investigations differ only in the positioning of a phenylalaninol residue at the $\mathrm{C}$-terminal end of the molecule. During the course of studies on the synthesis of alamethicin, we have prepared a number of oligopeptides containing Aib residues. This paper presents results of ${ }^{i} \mathrm{H}$ NMR studies of peptides incorporating $\mathrm{Aib}$ and describes a highly folded conformation in solution, for the tetrapeptide Z-Aib-ProAib-Ala-OMe, which constitutes the amino terminal sequence of alamethicin. ${ }^{16.17}$ In a preliminary report ${ }^{21}$ we have described the incipient $3_{10}$ helical structure of the tetrapeptide in the solid state. The results of these $x$-ray diffraction studies are also discussed in terms of the $3_{10}$ helical conformation postulated on the basis of ${ }^{1} \mathrm{H}$ NMR experiments.

\section{Experimental Section}

Synthesis of Peptides. Amino acid methyl ester hydrochlorides were prepared by the thionyl chloride-methanol procedure.** Free esters were obtained by dissolving the hydrochloride in saturated $\mathrm{Na}_{2} \mathrm{CO}_{3}$ solution and extracting the ester into $\mathrm{CH}_{2} \mathrm{Cl}_{2}$. Benzyloxycarbonyl( $\gamma$-aminoisobutyric acid (Z-Aib) was prepared by the SchottenBaumann procedure." Melting points are uncorrected. Optical rotations were measured in methanol solutions at $25^{\circ} \mathrm{C}$ on a JobinYvon polarimeter or a Jasco 5-20 spectropolarimeter. All compounds were checked for homogeneity by TLC on silica gel using the solvent system $5 \% \mathrm{CH}_{3} \mathrm{OH} / 95 \% \mathrm{CHCl}_{3}$ for protected peptide esters and $85 \%$ $\mathrm{CHCl}_{3} / 10 \% \mathrm{CH}_{3} \mathrm{OH} / 5 \% \mathrm{CH}_{3} \mathrm{COOH}$ for protected peptide acids.

Benzyloxycarbonyl-a-aminoisobutyrylprolyl Methyl Ester (ZAib-Pro-OMe). ${ }^{23}$ Proline methyl ester $(1.5 \mathrm{~g})$ was added to a solution of Z-Aib $(2.6 \mathrm{~g})$ in $15 \mathrm{~mL}$ of $\mathrm{CH}_{2} \mathrm{Cl}_{2}$ at 0 'C, followed by dicyclohexylcarbodiimide (DCC, $2.16 \mathrm{~g}$ ) in $5 \mathrm{~mL}$ of $\mathrm{CH}_{2} \mathrm{Cl}_{2}$. The mixture was stirred overnight at room temperature. After the precipitated dicyclohexylurea was filtered off, the filtrate was washed successively with $1 \mathrm{~N} \mathrm{HCI}, \mathrm{H}_{2} \mathrm{O}$, and $1 \mathrm{~N} \mathrm{NaHCO}$. The organic layer was dried over $\mathrm{Na}_{2} \mathrm{SO}_{4}$ and evaporated to yield an oil $(2.9 \mathrm{~g}, 80 \%):[\alpha]^{25} \mathrm{D}$ $-30.4^{\prime}$ (c $\left.1.2, \mathrm{CH}_{3} \mathrm{OH}\right) ;{ }^{1} \mathrm{H} \mathrm{NMR}\left(\mathrm{CDCl}_{3}\right) 1.47(\mathrm{~s}, 3 \mathrm{H}), 1.57(\mathrm{~s}$, $3 \mathrm{H}) .1 .82(\mathrm{~m}, 4 \mathrm{H}), 3.45(\mathrm{~m}, 2 \mathrm{H}), 3.62(\mathrm{~s}, 3 \mathrm{H}), 4.5(\mathrm{~m}, 1 \mathrm{H}), 5.1(\mathrm{~s}$, $2 \mathrm{H}), 6.33(\mathrm{~s}, \mathrm{I} \mathrm{H}), 7.2(\mathrm{~s}, 5 \mathrm{H})$.

Benzyloxycarbonyl- $\alpha$-aminoisobutyrylprolyl- $\alpha$-aminoisobutyryl Methyl Ester (1, Z-Aib-Pro-Aib-OMe). Z-Aib-Pro-OMe (2.9 g) was dissolved in methanol $(5 \mathrm{~mL})$ and $5 \mathrm{~mL}$ of $2 \mathrm{~N} \mathrm{NaOH}$ was added. After the solution had stood for $12 \mathrm{~h}$ at room temperature $30 \mathrm{~mL}$ of $\mathrm{H}_{2} \mathrm{O}$ was added and the solution extracted with ethyl acetate. The aqueous layer was acidified with $2 \mathrm{~N} \mathrm{HCI}$ and extracted with ethyl acetate $(4 \times 25 \mathrm{~mL})$. The ethyl acetate layer was dried and evaporated to yield $\mathrm{Z}$-Aib-Pro-OH as an oil $(2.3 \mathrm{~g}, 88 \%)$. The oil was dissolved in $15 \mathrm{~mL}$ of $\mathrm{CH}_{2} \mathrm{Cl}_{2}$ and cooled to $0^{\circ} \mathrm{C}$. A solution of Aib-OMe $(0.8$ g) in $3 \mathrm{~mL}$ of $\mathrm{CH}_{2} \mathrm{Cl}_{2}$ was added, followed by dicyclohexylcarbodiimide $(1.45 \mathrm{~g})$ in $4 \mathrm{~mL}$ of $\mathrm{CH}_{2} \mathrm{Cl}_{2}$. The mixture was stirred at room temperature for $24 \mathrm{~h}$ and the precipitated urea was filtered. The filtrate was washed successively with $1 \mathrm{NHCI}, \mathrm{H}_{2} \mathrm{O}$, and $1 \mathrm{~N} \mathrm{NaHCO}_{3}$ and dried. Evaporation yielded an oily residue that solidified on addition of petroleum ether. The tripeptide ester was recrystallized from methanol-ether: yield $2.1 \mathrm{~g}(75 \%)$; $\mathrm{mp} 154^{\circ} \mathrm{C}:[\alpha]^{25} \mathrm{D}-5.0^{\circ}$ (c 0.4 , $\mathrm{CH}_{3} \mathrm{OH}$ ). Anal. Calcd for $\mathrm{C}_{22} \mathrm{H}_{31} \mathrm{O}_{6} \mathrm{~N}_{3}: \mathrm{C} .60 .96 ; \mathrm{H}, 7.16 ; \mathrm{N}, 9.7$. Found: C, 61.32; H, 7.28; N, 9.4.

Benzyloxycarbonyl- $\alpha$-aminoisobutyrylprolyl- $\alpha$-aminoisobutyrylalanyl Methyl Ester (2, Z-Aib-Pro-Aib-Ala-OMe). Z-Aib-Pro-Aib$\mathrm{OMe}(2.1 \mathrm{~g})$ was saponified using methanol-2 $\mathrm{N} \mathrm{NaOH}$ as described for Z-Aib-Pro-OMe, yield $1.7 \mathrm{~g}(85 \%)$, mp $195^{\circ} \mathrm{C}$.

Alanine methyl ester (Ala-OMe, $0.21 \mathrm{~g}$ ) was added to a stirred suspension of Z-Aib-Pro-Aib-OH $(0.77 \mathrm{~g})$ in $10 \mathrm{~mL}$ of $\mathrm{CH}_{2} \mathrm{Cl}_{2}$. A clear solution resulted after a few minutes. Dicyclohexylcarbodiimide $(0.31 \mathrm{~g})$ in $2 \mathrm{~mL}$ of $\mathrm{CH}_{2} \mathrm{Cl}_{2}$ was added and the mixture stirred for 36 $\mathrm{h}$ at room temperature. The dicyclohexylurea was filtered off and the filtrate washed with $1 \mathrm{~N} \mathrm{HCI}, \mathrm{H}_{2} \mathrm{O}$, and $1 \mathrm{~N} \mathrm{NaHCO}_{3}$. Drying and evaporation of the organic layer yielded the tetrapeptide as a solid. Recrystallization from methanol-ether gave needle-shaped crystals: yield $0.63 \mathrm{~g}(70 \%)$; mp $145^{\circ} \mathrm{C}:[\alpha]^{25} \mathrm{D}-8.75^{\circ}\left(\mathrm{c} 0.4, \mathrm{CH}_{3} \mathrm{OH}\right)$. Anal. Calcd for $\mathrm{C}_{25} \mathrm{H}_{36} \mathrm{O}_{7} \mathrm{~N}_{4}: \mathrm{C}, 59.52 ; \mathrm{H}, 7.14 ; \mathrm{N}, 11.1$ I. Found: C, 59.02 $\mathrm{N}, 11.27$. Hydrogen analysis was not obtained. The molecular weight determined by X-ray methods ${ }^{2 !}$ was 503.3 (calcd, 504). ${ }^{1} \mathrm{H}$ NMR spectra were in full agreement with the structure.

The model pcptides Z-Aib-Ala-OMe $\left(\mathrm{mp} 70^{\circ} \mathrm{C}\right.$, $[\alpha]^{25} \mathrm{D}-6.0^{\prime}(c$ $\left.0.4, \mathrm{CH}_{3} \mathrm{OH}\right)$ ), Z-Ala-Aib-Ala-OMe $\left(\mathrm{mp} 148^{\circ} \mathrm{C} .[\mathrm{a}]^{25} \mathrm{D}-48.8^{\circ}\right.$ (c $\left.0.4, \mathrm{CH}_{2} \mathrm{OH}\right)$ ), and Boc-Val-Aib-OMe (mp $115-118^{\circ} \mathrm{C},[\alpha]^{25} \mathrm{D}$ $-27.5^{\prime}\left(\mathrm{c} 0.4, \mathrm{CH}_{3} \mathrm{OH}\right)$ ) were synthesized using the above procedures. The compounds were chromatographically homogeneous and yielded ${ }^{1} \mathrm{H}$ NMR spectra in full agreement with the expected structures. 
Table I

\begin{tabular}{|c|c|c|c|c|c|}
\hline \multirow[b]{2}{*}{ compd $^{d}$} & \multirow[b]{2}{*}{ proton } & \multicolumn{4}{|c|}{$\mathrm{NH}$ chemical shifts and $t_{1 / 2^{a}}$} \\
\hline & & $\mathrm{CDCl}_{3}$ & $\left(\mathrm{CD}_{3}\right)_{2} \mathrm{SO}$ & $t_{1 / 2} \mathrm{CDCl}_{3}$ & $l_{1 / 2}\left(\mathrm{CD}_{3}\right)_{2} \mathrm{SO}$ \\
\hline \multirow[t]{3}{*}{ Z-Aib-Pro-Aib-Ala-OMe (2) } & Aib I & 5.83 & 7.93 & $48 \mathrm{~min}$ & $16 \mathrm{rnin}$ \\
\hline & Aib 3 & 7.21 & 7.75 & $20 \mathrm{~h}$ & $6.7 \mathrm{~h}$ \\
\hline & Ala 4 & 7.52 & 7.49 & $20 \mathrm{~h}$ & $12.1 \mathrm{~h}$ \\
\hline \multirow{2}{*}{ Z-Aib-Pro-Aib-OMe ${ }^{b}(1)$} & Aib 1 & 5.53 & 8.04 & & $19 \mathrm{~min}$ \\
\hline & Aib 3 & 7.39 & 7.56 & & $24 \mathrm{~h}$ \\
\hline Z-Aib-Pro-OMe & Aib 1 & 6.33 & 7.74 & $3.5 \mathrm{rnin}$ & $2 \mathrm{~min}$ \\
\hline \multirow[t]{2}{*}{$\mathrm{Z}$-Aib-Ala-OMe } & Aib I & 5.28 & 7.23 & 31 rnin & $18 \mathrm{rnin}$ \\
\hline & Ala 3 & 6.76 & 7.84 & $40 \mathrm{rnin}$ & $I \mathrm{~min}$ \\
\hline \multirow[t]{3}{*}{ Z-Ala-Aib-Ala-OMe } & Ala 1 & 5.64 & 7.52 & $7.3 \mathrm{rnin}$ & \\
\hline & Aib 2 & 6.86 & 8.10 & $1.8 \mathrm{~h}$ & \\
\hline & Ala 3 & 7.09 & & $1.8 \mathrm{~h}$ & \\
\hline \multirow[t]{2}{*}{ Boc-Val-Aib-OMe } & Val 1 & 5.14 & 6.44 & $10 \mathrm{rnin}$ & \\
\hline & Aib 2 & 6.66 & 8.15 & $1.5 \mathrm{~h}$ & \\
\hline
\end{tabular}

${ }^{a} t_{1 / 2}$ is the measured half-life for the first-order decay of the $\mathrm{NH}$ signals. 6 values are in parts per million from $\left(\mathrm{CH}_{3}\right)_{4} \mathrm{Si}^{b} t_{1 / 2}$ measurements for 1 in $\mathrm{CDCl}_{3}$ are not reported as $\mathrm{Aib}(3) \mathrm{NH}$ resonance overlaps with the phenyl resonance. ${ }^{C}$ In $\left(\mathrm{CD}_{3}\right)_{2} \mathrm{SO}$ only one Ala $\mathrm{NH}$ was observed, while the other was obscured by the phenyl resonance. The assignment of this resonance to Ala (1) NH is not unambiguous. ${ }^{d}$ The $J_{\mathrm{NH}-\mathrm{C}^{\alpha} \mathrm{H}}$ values for the Ala residues are as follows: Z-Aib-Pro-Aib-Ala-OMe, Ala (4), $J=7.0 \pm 0.2\left(\mathrm{CDCl}_{3}\right), 7.3 \pm 0.2 \mathrm{~Hz}\left(\mathrm{CD}_{3}\right)_{2} \mathrm{SO} ; \mathrm{Z}$-Aib-Ala-OMe. Ala (2), $7.2 \pm 0.5 \mathrm{~Hz}$; Z-Ala-Aib-Ala-OMe. Ala (1), Ala (3), $J=7.0 \mathrm{~Hz}\left(\mathrm{CDCl}_{3}\right)$ for both residues.

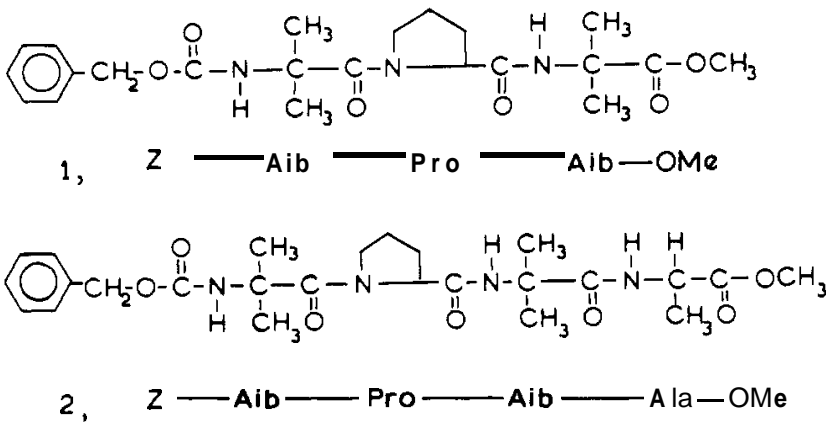

Figure 1. Sequences of peptides

NMR Measurements. ' $\mathrm{H}$ NMR spectra were recorded on a Varian HA-100 spectrometer at $28^{\circ} \mathrm{C}$. Deuterium exchange experiments in $\left(\mathrm{CD}_{3}\right)_{2} \mathrm{SO}$ were done by addition of $\mathrm{D}_{2} \mathrm{O}$ to a concentration of $10 \%$. The exchange experiments in $\mathrm{CDCl}_{3}$ were carried out by saturating the solvent with $\mathrm{D}_{2} \mathrm{O}$. In all experiments the peptide concentration was $50 \mathrm{mg} / \mathrm{mL}$

X-ray Diffraction. X-ray crystallographic studies were carried out as described elsewhere. ${ }^{21}$ A final $R$ value of 0.031 , using 2378 reflections, was obtained. The estimated standard deviation in the heavy atom coordinates is $0.003 \AA$.

\section{Results and Discussion}

Table I summarizes the chemical shifts of the $\mathrm{N} \mathrm{H}$ protons in Z-Aib-Pro-Aib-Ala-OMe (2), Z-Aib-Pro-Aib-OMe (1) (Figure 1), and in model peptides containing Aib residues. The assignment of the resonances at $\delta 5.83$ and 7.21 in the tetrapeptide, in $\mathrm{CDCl}_{3}$, to the amide hydrogens of Aib (1) and Aib (3), respectively, follows from a comparison of the $\mathrm{NH}$ chemical shifts observed in the peptides Z-Aib-Ala-OMe, Z-Aib-Pro-OMe, and Z-Aib-Ala-Aib-OMe. In these peptides the assignment of the $\mathrm{NH}$ resonances is unequivocal, since the Aib NH appears as a singlet and the Ala N H as a doublet. The urethan $\mathrm{NH}$ appears consistently at higher field in $\mathrm{CDCl}_{3}$, as compared to the peptide $\mathrm{NH}$ resonance, in all the compounds listed in Table I. The upfield shift of urethan NH peaks has also been noted in earlier studies. ${ }^{24}$ The assignment of the doublet at $\delta 7.52$ in the tetrapeptide spectrum to Ala (4) $\mathrm{N} \mathrm{H}$ is unequivocal. The assignment of the Aib (1) and Aib (3) N H groups in the spectrum of 2 in $\left(\mathrm{CD}_{3}\right)_{2} \mathrm{SO}$ was made by monitoring the change in chemical shifts in $\mathrm{CDCl}_{3} /\left(\mathrm{CD}_{3}\right)_{2} \mathrm{SO}$ mixtures as a function of $\left(\mathrm{CD}_{3}\right)_{2} \mathrm{SO}$ concentration. The Aib (I) and Aib (3) N H resonances in the tripeptide Z-Aib-ProAib-OMe (1) are assigned using similar comparisons.

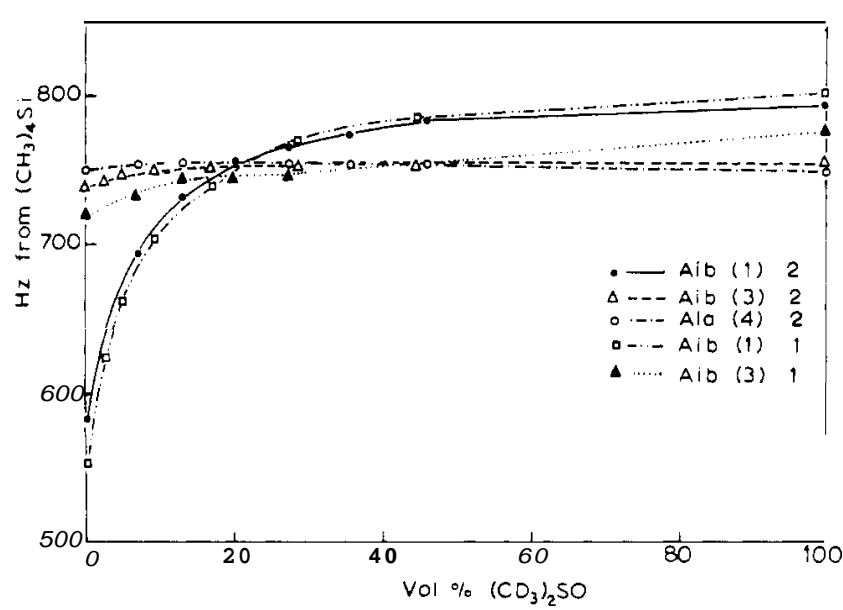

Figure 2. Chemical shifts of the $\mathrm{NH}$ proton resonances of $\mathbf{1}$ and $\mathbf{2}$ in mixtures of $\mathrm{CDCl}_{3}$ and $\left(\mathrm{CD}_{3}\right)_{2} \mathrm{SO}$

The rates of exchange of the various amide and urethan hydrogens in these molecules were measured by monitoring the disappearance of the corresponding proton resonances on addition of $\mathrm{D}_{2} \mathrm{O}$. These results are presented in Table I. A comparison of the exchange half-lives $\left(t_{1 / 2}\right)$ of the tetrapeptide (2) and tripeptide (1) with those of Z-Ala-Aib-Ala-OMe, Z-Aib-Pro-OMe, Z-Aib-Ala-OMe, and Boc-Val-Aib-OMe clearly shows that $\mathbf{2}$ contains two slowly exchanging amide hydrogens and that 1 has one slowly exchanging amide hydrogen. In all the compounds studied the urethan hydrogen underwent rapid exchange. It may be noted that, while both Aib (3) and Ala (4) NH resonances in 2 yielded $t_{1 / 2}>20 \mathrm{~h}$ in $\mathrm{CDCl}_{3}$, the corresponding $t_{1 / 2}$ values in $\left(\mathrm{CD}_{3}\right)_{2} \mathrm{SO}$ are significantly shorter. While a direct comparison of exchange rates in $\mathrm{CDCl}_{3} / \mathrm{D}_{2} \mathrm{O}$ and $\left(\mathrm{CD}_{3}\right)_{2} \mathrm{SO} / \mathrm{D}_{2} \mathrm{O}$ systems is not valid, it is interesting that the $t_{1 / 2}$ value for Aib (3) N H in the tripeptide 1 in $\left(C_{3}\right)_{2} \mathrm{SO} / \mathrm{D}_{2} \mathrm{O}$ is greater than $24 \mathrm{~h}$. The corresponding value for 1 in $C \mathrm{CDI}_{3} / \mathrm{D}_{2} \mathrm{O}$ could not be determined owing to overlap of the $\mathrm{NH}$ peak with the phenyl resonances of the benzyloxycarbonyl protecting group.

Figure 2 shows the effect of altering the solvent on the chemical shifts of the $\mathrm{NH}$ resonances of $\mathbf{1}$ and $\mathbf{2}$. Increasing the concentration of $\left(\mathrm{CD}_{3}\right)_{2} \mathrm{SO}$ causes a large downfield shift of the urethan Aib (1) $\mathrm{NH}$ group of the tripeptide 1, while the Aib (3) NH resonance is left almost unaffected. In the tetrapeptide 2, the Aib (1) NH moves rapidly downfield with increasing $\left(\mathrm{CD}_{3}\right)_{2} \mathrm{SO}$ concentration, while the Aib (3) and Ala 


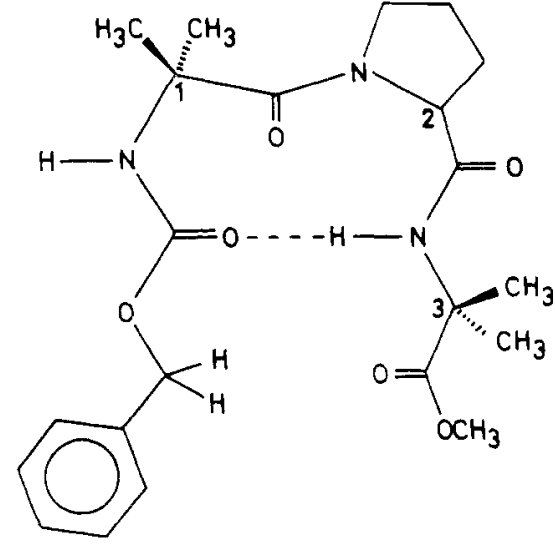

Figure 3. $\beta$-Turn conformation of Z-Aib-Pro-Aib-OMe (1)

(4) amide protons are less affected. The chemical shift values of the $\mathrm{NH}$ resonances, in the Aib-containing peptides being studied, in $\mathrm{CDCl}_{3}$ and $\left(\mathrm{CD}_{3}\right)_{2} \mathrm{SO}$ are listed in Table I. Amide $\mathrm{NH}$ protons exposed to the solvent should show significant chemical shift variations on going from a poor hydrogen bond accepting solvent like $\mathrm{CDCl}_{3}$ to a good hydrogen bond acceptor like $\left(\mathrm{CD}_{3}\right)_{2} \mathrm{SO}$. Solvent shifts may therefore be used to delineate exposed and shielded peptide hydrogens. ${ }^{25}$ The results presented in Table I show that the Aib (3) and Ala (4) N H resonances in $\mathbf{2}$ and the Aib (3) N H resonance in $\mathbf{1}$ show significantly smaller chemical shift changes on going from $\mathrm{CDCl}_{3}$ to $\left(\mathrm{CD}_{3}\right)_{2} \mathrm{SO}$ than the other $\mathrm{N} \mathrm{H}$ resonances listed. Considered together with the deuterium exchange data, these results suggest that, in the tripeptide 1, the Aib (3) N H hydrogen is shielded from the solvent, and that in the tetrapeptide $\mathbf{2}$, the Aib (3) and Ala (4) NH hydrogens are shielded from the solvent.

The observation of solvent-shielded amide hydrogens in 1 and $\mathbf{2}$ argues for the presence of well-defined structures in solution. The ten-atom hydrogen bonded $\beta$ turn, ${ }^{26}$ involving the Aib (3) NH in a hydrogen bond with the urethan carbonyl group, is consistent with the data presented for the tripeptide 1 (Figure 3). For the tetrapeptide $\mathbf{2}$ structures involving both Aib (3) and Ala (4) amide hydrogens in intramolecular hydrogen bonds need to be considered. Figure 4 shows two possible conformations for the tetrapeptide involving two intramolecular hydrogen bonds. The structure shown in Figure $4 \mathrm{~b}$ has been postulated for a tetrapeptide fragment of tropoelastin, Boc-Val-Pro-Gly-Gly-OMe in $\mathrm{CDCl}_{3} .{ }^{10}$ It has also been observed in the solid state for a collagenase substrate, $O$-bromocarbobenzoxy-Gly-Pro-Leu-Gly-Pro. ${ }^{27}$ However, For the tetrapeptide 2 the N H hydrogen of Aib (1) has been shown to be exposed to solvent, whereas the $\beta$ structure would require Aib (1) N H to be involved in an intramolecular hydrogen bond. Further Aib (1) cannot be stereochemically accommodated in the $\beta$ structure owing to unfavorable contacts of the geminal $\mathrm{CH}_{3}$ groups of Aib (1) with the $\delta \mathrm{CH}_{2}$ group of Pro (2). A consideration of the conformational energy map reported for Aib residues confirms that the $\beta$ structure $\left(\phi=-139^{\circ}, \psi=\right.$ $\left.+135^{\circ}\right)$ is energetically highly unfavorable. ${ }^{14} \mathrm{~A}$ structure that is compatible with the ${ }^{1} \mathrm{H}$ NMR data involving two consecutive $\beta$ turns with Aib (1)-Pro (2) and Pro (2)-Aib (3) at the respective corners is shown in Figure 4a. While the NMR data provide evidence only for the degree of solvent exposure of amide hydrogens, their involvement in hydrogen bonds remains to be conclusively established. The postulation of ten-atom hydrogen bonded $\beta$-turn structures follows from the widespread occurrence of $\beta$ turns in oligopeptides ${ }^{28-30}$ and proteins, demonstrated by X-ray crystallography, ${ }^{31-33}$ Further, conformational energy calculations for acetyl $\alpha$-aminoisobutyryl- $\mathrm{N}$-methylamide $\left(\mathrm{Ac}-\mathrm{Aib}-\mathrm{NHCH}_{3}\right)$ indicate the presence

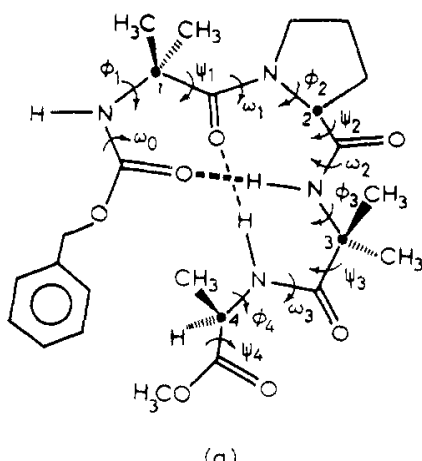

(a)

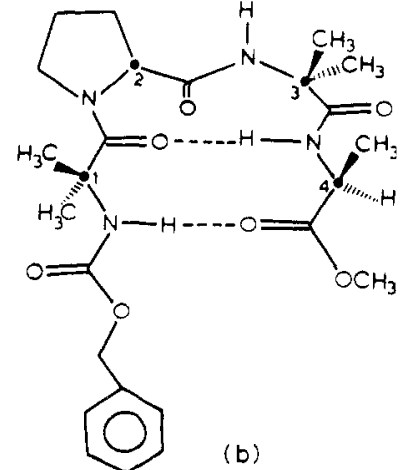

(b)
Figure 4. (a) Consecutive $\beta$ turn or $3_{10}$ helical model for Z-Aib-Pro-AibAla-OMe (2).(b) Antiparallel 6-sheet conformation for 2.

of minima only in the right- and left-handed $3_{10}$ and a-helical regions. ${ }^{14}$ Consequently the $\beta$ turns in the tetrapeptide, which contains two $\mathrm{L}$ amino acid residues, may fall into the type III category $\left(\phi=-60^{\circ}, \psi=-30^{\circ}\right)$. This is reasonably close to the values for the right-handed $\alpha$ helix $\left(\phi \sim-\mathrm{SO}^{\prime \prime}, \psi \sim-50^{\circ}\right)$. The conformation shown in Figure $4 \mathrm{~b}$ then forms an incipient $3_{10}$ helical structure. ${ }^{34}$

The vicinal coupling constant between the amide hydrogen and the $C^{\prime \prime}$ proton has been extensively used in determining the conformational angle $\phi$ in peptides. ${ }^{2}$ Alkylation at $\mathrm{C}^{\alpha}$ in Aib residues removes this information from the spectrum. For the tetrapeptide 2 the only vicinal coupling constant obtainable is for Ala (4). The observed ${ }^{2} J_{\mathrm{HH}}$ of $7 \mathrm{~Hz}$ in $\mathrm{CDCl}_{3}$ and $7.3 \mathrm{~Hz}$ in $\left(\mathrm{CD}_{3}\right)_{2} \mathrm{SO}$ suggests a conformationally averaged value for $\phi_{4}$ in solution. This is consistent with the $3_{10}$ helical structure shown in Figure $4 \mathrm{~b}$ but not with the $\beta$ structure. It may be noted that ${ }^{3} J_{\mathrm{HH}}$ for both Ala residues in Z-Ala-Aib-Ala-OMe is $-7 \mathrm{~Hz}$. A consistent feature of the ' $\mathrm{H}$ NMR spectra of the compounds listed in Table I is the nonequivalence of the benzylic $-\mathrm{CH}_{2}$ - protons of the benzyloxycarbonyl group, in the peptides postulated to have a well-defined conformation in solution, involving the urethan carbonyl group as a hydrogen bond acceptor. The $\mathrm{CH}_{2}$ protons $(-65)$ appear as an $\mathbf{A B}$ quartet in the tripeptide 1 in $\mathrm{CHCl}_{3}$ and $\left(\mathrm{CD}_{3}\right)_{2} \mathrm{SO}$ and in the tetrapeptide 2 in $\mathrm{CDCl}_{3}$. These protons, however. yielded a singlet in Z-Aib-Pro-OMe, Z-Aib-Ala-OMe, and Z-AlaAib-Ala-OMe. Among the related compounds examined benzyloxycarbonyl- $\alpha$-aminoisobutyrylprolyl- $N$-methylamide (Z-Aib-Pro- $\mathrm{NHCH}_{3}$ ) showed an AB quartet for the benzylic protons in $\mathrm{CDCl}_{3}$. The crystal structure of this molecule shows the presence of a type III $\beta$ turn involving the urethan carbonyl and the methyl amide NH group in a hydrogen bond. ${ }^{35}$ These observations suggest that enhanced chemical shift nonequivalence of the $-\mathrm{CH}_{2}$ - protons follows the involvement of the urethan carbonyl group in stabilizing specific conformations. While the $\mathrm{CH}_{2}$ protons are diastereotopic in these peptides and may be expected to show anisochrony in the absence of specific conformational effects, ${ }^{36,37}$ the observations support the view that conformational factors appear to determine the magnitude of nonequivalence. Figure 5 shows the effect of addition of trifluoroacetic acid (TFA) on the $\mathrm{CH} 2$ quartet observed for the tetrapeptide 2 in $\mathrm{CDCl}_{3}$. Increasing the acid concentration leads to a collapse of the AB quartet to a broad singlet at about $4 \%(\mathrm{v} / \mathrm{v})$ TFA in $\mathrm{CDCl}_{3}$. The structure breaking effect of TFA on polypeptides is well documented. ${ }^{38}$ The results reported here further strengthen our contention that the tetrapeptide $\mathbf{2}$ adopts a folded conformation in $\mathrm{CDCl}_{3}$. Addition of TFA then leads to an unfolding of the tetrapeptide structure. The tetrapeptide 2 shows only a singlet for the benzylic $\mathrm{CH} 2$ group in $\left(\mathrm{CD}_{3}\right)_{2} \mathrm{SO}$. The exchange rate of the Aib (3) amide hydrogen in $\mathbf{2}$ is significantly faster than the exchange rate of the corresponding $\mathrm{NH}$ group in the tripeptide $\mathbf{1}$ in $\left(\mathrm{CD}_{3}\right)_{2} \mathrm{SO}$. These results may 


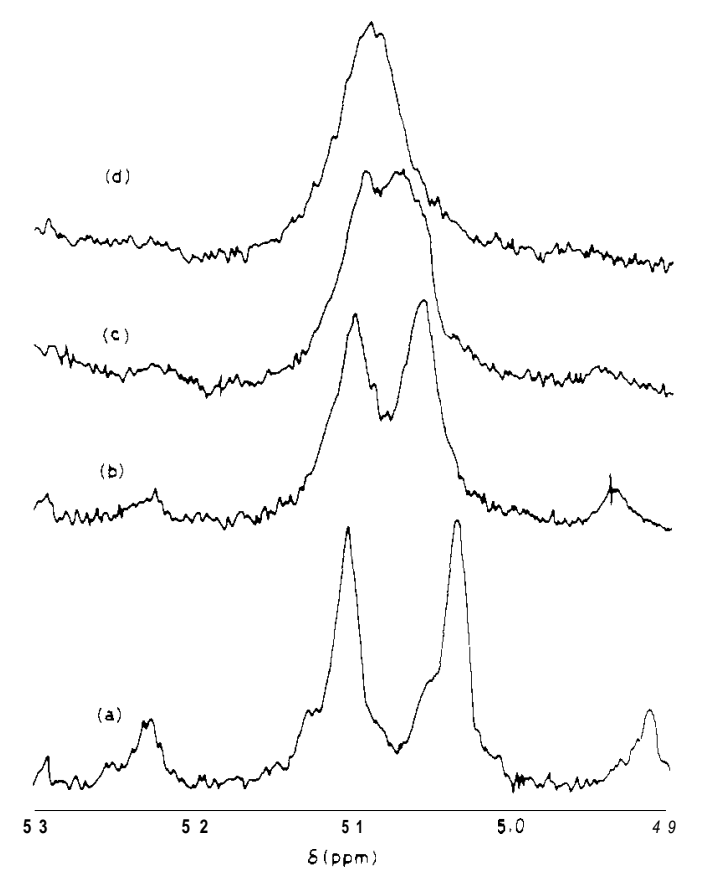

Figure 5. $\mathrm{CH}_{2}$ proton resonances of the benzyloxycarbonyl group in $\mathrm{Z}$ Aib-Pro-Aib-Ala-OMe (2). (a) $\mathrm{CDCl}_{3}$, (b) $\mathrm{CDCl}_{3} / \mathrm{TFA}$ (40:1), (c) $\mathrm{CDCl}_{3} / \mathrm{TFA}(26: 1)$, (d) $\mathrm{CDCl}_{3} / \mathrm{TFA}(16: 1)$.

be tentatively interpreted, as resulting from a loosening of the Aib (I)-Pro (2) bend in the tetrapeptide in $\left(\mathrm{CD}_{3}\right)_{2} \mathrm{SO}$. A more rigorous comparison of the folded forms of 2 in $\mathrm{CDCl}_{3}$ and $\left(C D_{3}\right)_{2} \mathrm{SO}$ is not possible with the available experimental data.

The ${ }^{1} \mathrm{H}$ NMR results presented above strongly support the presence of defined conformations for the acyclic tri- and tetrapeptides 1 and 2 in $\mathrm{CDCl}_{3}$ and $\left(\mathrm{CD}_{3}\right)_{2} \mathrm{SO}$. Theoretical calculations of the dipeptide conformational energy map for Aib residues show that type III $\beta$ turns can accommodate these residues. The NMR data provide compelling evidence for the presence of intramolecular hydrogen bonds in $\mathbf{1}$ and $\mathbf{2}$ in solution, which are compatible with structures involving type III $\beta$ bends. However, alternative hydrogen bonding schemes involving $1-3$ (7 atom) and 15 (13 atom) hydrogen bonds cannot be ruled out from the ${ }^{1} \mathrm{H}$ NMR data alone. Indeed $1 \leftarrow 3$ hydrogen bonds have been postulated in solution for amino acid derivatives and peptides ${ }^{39.40}$ and have also been observed in the crystal structure of dihydrochlamydocin, a cyclic tetrapeptide containing one Aib residue. 41 I $\leftarrow 5$ hydrogen bonds are found extensively in a-helical segments in proteins. ${ }^{42}$ Since an unequivocal demonstration of the 310 helical structure shown in Figure 4a did not appear to be feasible, exclusively on the basis of ${ }^{1} \mathrm{H}$ NMR studies, a singlecrystal X-ray diffraction study of the tetrapeptide 2 , was carried out.

Crystal Structure of Z-Aib-Pro-Aib-Ala-OMe. A preliminary report of the structure at an earlier stage of refinement has been published. ${ }^{21}$ The projection of the molecule down the $z$ axis is shown in Figure 6. The structure shows the presence of two intramolecular hydrogen bonds between the urethan $\mathrm{CO}$ and the $\mathrm{NH}$ group of $\mathrm{Aib}$ (3) and the $\mathrm{CO}$ group of $\mathrm{Aib}$ (1) and the $\mathrm{NH}$ group of Ala (4) .The N...O distances are 3.17 and $3.06 \AA$, respectively. These distances compare well with reported values for hydrogen bond lengths in crystal structures of peptides. ${ }^{30}$ The presence of a $1 \leftarrow 5$ hydrgen bond, corresponding to an a-helical conformation, is ruled out by the large separation of $4.12 \AA$ between $\mathrm{O}(2)$ of the urethan group and $N(4)$ of Ala (4). The crystal structure also does not provide any evidence for $1 \leftarrow 3$ hydrogen bonds. The conformational angles $(\phi, \psi$, and $\omega)$ for the structure are listed in Table II. The ob-

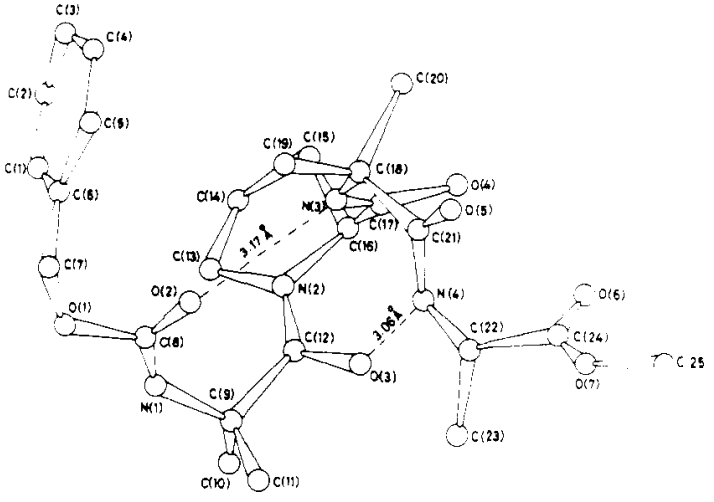

Figure 6. Molecular structure of Z-Aib-Pro-Aib-Ala-OMe (2) viewed down the $z$ axis

Table II. Conformational Angles ${ }^{a}$ in the Crystal Structure of ZAib-Pro-Aib-Ala-OMe

\begin{tabular}{crrrr}
\hline angle & Aib (1) & Pro (2) & Aib (3) & Ala (4) \\
\hline$\phi$ & -51.2 & -54.8 & -72.0 & -67.8 \\
$\psi$ & -45.3 & -35.8 & -11.2 & 155.6 \\
$\omega^{b}$ & -171.3 & 170.1 & -173.2 &
\end{tabular}

$a$ The convention followed is that proposed in ref $44{ }^{b}$ The angle $\omega_{0}$ defined by $\mathrm{O}(1)-\mathrm{C}(8)-\mathrm{N}(1)-\mathrm{C}(9)$ is $-175.9^{\circ}$.

served values for $\phi$ and $\psi$ are in fairly good agreement with the values expected for type III $\beta$ turns. Full details of the crystal structure will be reported separately.

The structure observed for the tetrapeptide $\mathbf{2}$ in the crystalline state confirms that the incipient 310 helical conformation is indeed an acceptable structure. The existence of two solvent-shielded arnide hydrogens in $\mathbf{2}$ and one solvent-shielded arnide hydrogen in $\mathbf{1}$ leads us to conclude that the tetrapeptide maintains the $3_{10}$ helical conformation in solution while the tripeptide adopts a type III $\beta$-bend structure. Further support for the type III $\beta$-bend structure in 1 comes from X-ray diffraction studies of Z-Aib-Pro- $\mathrm{NHCH}_{3}$, which shows the type III $\beta$ turn with Aib and Pro residues at the corners ${ }^{35}$ Our results substantiate earlier suggestions that Aib residues are sterically hindered ${ }^{13,14}$ and restrict conformational flexibility in small peptides. The property of Aib residues to occur in type III $\beta$-bend conformations has received further support from a single-crystal $X$-ray study of $p$-toluenesulfonyl-(Aib) $5^{-}$ OMe, which shows three consecutive $\beta$ bends in the solid state. We shall elaborate on these results elsewhere. Recently, fiber diffraction evidence has been presented for poly ( $\alpha$-aminoisobutyric acid) which suggests that the polypeptide adopts a 310 helical conformation in the solid state. ${ }^{43}$

Acknowledgments. We are grateful to the University Grants Commission for financial support and to the Department of Organic Chemistry for the use of the HA-I00 spectrometer. R.N. is the recipient of a fellowship from the Department of Atomic Energy, Government of India.

\section{References and Notes}

(1) Craig, L. C.; Cowburn, D.; Bleich, H. Annu. Rev. Biochem. 1975, 44, $477-490$.

(2) Wyssbrod, H.: Gibbons, W. A. Surv. Prog. Chem. 1973, 6, 207-325

(3) Deber. C. M.: Madison, V.: Blout. E. R. Acc. Chem. Res. 1976, 9, $106-$ 113.

(4) Howard, J. C.: Ali, A.: Scheraga, H. A.; Momany, F. A. Macromolecules 1975, 8, 607-622.

(5) Goodman, M.; Toniolo, C.; Naider, F. In "Peptides, Polypeptides and Proteins", Blout. E. R.; Bovey, F. A.: Goodman, M.:Lotan, N. .Ed.: Wilev̧: New York, N.Y 1974; pp 308-319.

(6) Pysh, E. S.; Toniolo, C. J. Am. Chem. Soc. 1977, 99,6211-6219.

(7) Kopple, K. D.: Go, A.: Pilipauskas, D. R. J. Am. Chem. Soc. 1975, 97, $6830-6838$. 
(8) Kopple K. D : Go, A Biopolymers 1976, 75 1701-1715.

(9) Kopple, K. D.; Go, A. In "Peptides: Chemistry, Structure and Biology", Walter, R.; Meienhofter, J., Ed.; Ann Arbor Science Publishers: Ann Arbor, Mich., 1975; pD 139-143.

(10) Abu Khaled, Md. ;Renugopalakrishnan, V.; Urry, D. W. J. Am. Chem. Soc 1976, 98, 7547-7553.

(11) Leplawy, M. T. Jones, D. S.; Kenner, G. W.: Sheppard, R. C. Tetrahedron 1960, 11. 39-51.

(12) Jones. D. S.; Kenner, G. W.; Preston, J.; Sheppard, R. C. J. Chem. Soc $1965,6227-6239$

(13) Marshall, G. R.; Bosshard. H. E. Circ. Res. Suppl. // 1972, 30, 143-150

(14) Burgess, A. W. Leach, S. J. Biopolymers 1973, 12,2599-2605

(15) Pletnev, V. Z.; Gromov, E. P.; Popov, E. M. Khim. Prir. Soedin. 1973, 9, $224-229$

(16) Martin, D. R.; Williams, R. J. P. Biochem. J. 1976, 753, 181-190.

(17) Pandey, R. C.; Carter Cook, Jr., J.; Rinehart, Jr., K. L. J. Am. Chem. Soc $1977,99,8469-8483$

(18) Jung, G.; Konig, W. A.; Liebfritz, D.; Ooka, T . Janko, K.; Boheim, G. Biochim Biophys. Acta 1976, 433, 164-181

(19) Pandey, R. C.; Carter Cook, Jr., J.; Rinehart, Jr., K. L. J. Am. Chem. Soc 1977, 99, 5205-5206

(20) Pandey, R.; Meng, Hsi; Carter Cook. Jr., J.; Rinehart, Jr., K. L. J. Am. Chem. Soc. $1977,99,5203-5205$.

(21) Shamala, N.: Nagaraj, R.; Balaram. P. Biochem. Biophys. Res. Commun. 1977, 79, 292-298.

(22) Brenner, M.; Huber, W. Helv. Chim. Acta 1953, 36, 1109-1115.

(23) Gerig. J. T.; McLeod, R. S. J. Org. Chem. 1976, 47, 1653-1655

(24) Bystrov, V. F.; Portnova, S. L.; Tsetiin. V. I.: Ivanov, V. T. Ovchinnikov, Yu. A. Tetrahedron $1965,25,493-515$

(25) Pitner, T.P.: Urry, D. W. J.Am. Chem. Soc 1972, 94, 1399-1400

(26) Venkatachalam, C. M. Biopolymers 1968, 6, 1425-1436.
(27) Ueki. T: Bando, S.: Ashida, T.;Kakudo, M. Acta Crystallogr, Sect B 1971 27. 2219-2231.

(28) Chandrasekaran. R.: Lakshminarayanan, A. V.; Pandya, U. V.; Ramachandran, G. N. Biochim. Biophys. Acta 1973, 303, 14-27.

(29) Scott Zimmerman, S.; Scheraga, H. A. Biopolymers 1977, 16, 811843

(30) Karle, I. L. In ref 9, pp 139-143

(31) Chou, P. Y.; Fasman, G. D. J. Mol. Biol. 1977, 115, 135-175

(32) Lewis, P. N.:Momany, F. A.; Scheraga, H. A. Biochim.Biophys. Acta 1973 $303,211-229$

(33) Crawford, J. L.; Lipscomb, W. N.; Schellman. C. G. Proc. Natl. Acad. Sci. U.S.A. $1973,70,538-542$

(34) Donohue, J. Proc. Natl. Acad. Sci. U.S.A. 1953, 39,470-478.

(35) Shamala, N.; Nagaraj, R.; Venkataram Prasad, B. V.; Prashanth, D.;Balaram, P. international Symposium on Biomolecular Structure, Conformation, Function and Evolution, Madras, 1978, Abstract 130/H17.

(36) Reisse J.; Ottinger, R.; Bickart, P.; Mislow, K. J. Am. Chem. Soc. 1978 $100,911-915$

(37) Mislow, K.;Raban. M. Top Stereochem. 1967, 1, 1--38.

(38) Klotz, I.M.;Russo. S. F.: Hanlon, S.; Stake, M. A. J. Am. Chem. Soc 1964 $86,4774-4778$

(39) Abu Khaled, Md.; Urry. D. W.; Okamoto, K. Biochem. Biophys. Res. Commun. 1976, 72, 162-169.

(40) Avignon, M.; Huong, P. V.; Lascombe, J.; Marraud, M.; Neel, J. Biopoiymers $1969,8,69-89$

(41) Flippen, J. L.; Karle, I. L. Biopolymers 1976, 15, 1081-1092

(42) Dickerson, R. E.; Geis, I. "The Structure and Action of Proteins", Harper and Row: New York, N.Y., 1969

(43) Malcolm, B. R. Biopolymers 1977, 16, 2591-2592.

(44) IUPAC-IUBCommission on Biochemical Nomenclature Biochemistry 1970, 9,3471-3479. 